\title{
El quehacer del arquitecto en América Latinal
}

\section{Generalidades}

Hemos visto ya todo lo que destacó más en la historia de la arquitectura y el urbanismo durante el siglo XX (algunos sorprendidos lectores leerán esto quizá en el XXI). Vimos cuáles fueron los principales actores latinoamericanos del diseño, y la actitud inicial muy elitista de algunos profesionales americanos vinculados a los maestros de renombre y de algunos profesionales extranjeros radicados en nuestro continente, para luego aumentar su número cada vez más en un intento por recuperar el tiempo perdido y buscar una consubstanciación con los principios de una disciplina que los fascinó. Y en cierto sentido, en la tarea de proyectar hemos recorrido casi todos los caminos, copiando, imitando, deformando, y con todas las facelas de la responsabilidad profesional y del impulso creativo. Esta historia es de acción y posiblemente anecdótica. En pocos casos fue reflexiva. Pero cuando lo fue, sorprende su desconocimiento hasta hace poco. Como he ido documentando en el libro, casi siempre hubo una preocupación teórica por lo que se hacía. Sin embargo, no deja de resultar difícil discutir un cuerpo de ideas basado en el concepto mesiánico del arquitecto.

Hoy, al borde de la innecesidad de la inteligencia humana - pues para lo que hay que hacer la computadora es más eficaz, dicen algunos-, pensamos los muy viejos que la arquitectura tal como la quisimos no existe más. Que la teoría nos ahoga, que quisiéramos ser más libres y espontáneos, quisiéramos poder equivocarnos, como dijo hace poco un esludiante (las preocupaciones son siempre las mismas, parece) "aprender equivocándose"; sólo que al socializarse, el individuo se hace más cauto, pierde su inocencia: ¿quién pagará por mi equivocación? Después de levantar tantas barreras, defendiéndome de todos los posibles ataques, expondré lo que he encontrado. La arquitectura latinoamericana tiene los rasgos fundamentales que se pueden generalizar. Partiendo de una conciencia traumatizada de dependencia económica y alienación cultural, el inte- 
lectual latinoamericano ha desarrollado a lo largo de este siglo XX procesos de autoinspección y autocrítica que están dando resultados dignos de mención y que vamos a formular de este modo: cómo el problema de la identidad preocupa actualmente a los jóvenes. En ese sentido hemos planteado algunos argumentos posibles para su análisis.

\subsection{Conciencia de sí: identificación, identidad}

Respeto mucho a un arquilecto colombiano, Germán Téllez, por su humor e inteligencia: "Luzca una buena crisis de identidad. Sea un buen snob de su propia idenlidad, y confúndala ante sus congéneres con el problema de identificación. Mire su documento (cédula, tarjeta de crédito, permiso de conducir o pasaporte) para saber quién es. En la soledad de su estudio tómese la cabeza a dos manos y pregúntese a sí mismo qué está haciendo ahí, en tan exıraño lugar. Observe su diploma de arquitecto. ¿Qué le dice? O mejor aún. ¿Lo ha leído de veras, alguna vez?".

La conciencia tecnosocial da un tipo de relación de personas entre sí y de ellas con las cosas. Es decir, que nuestros comportamientos difieren de lo que se considera internacional; como personas nos consideramos a partir de nuestro sentimiento hedonista - me complazco porque soy- antes que de un sentido práctico; la practicidad no está interpretada como la cúspide de las filosofias, sino que toma a lo sumo un lugar importante en nuestra interpretación del mundo. Por otra parte, no establecemos lazos racionales con las cosas, como apartándonos de ellas, sino que las hacemos propiedad subjetiva y no objeto substancial de conocimiento; las usamos como si realmente las hubiéramos producido nosotros mismos, aunque no entendamos nada de su proceso de producción; por ejemplo, el comportamiento con un automóvil, un carro. El carro es una herramienta a nuestro servicio hedonista y no sólo a nuestro servicio práctico. Igual sucede con todas las cosas.

El convencimiento creativo no corresponde a la tipicidad. Estamos convencidos de que la ordenación del mundo tiene origen cada vez en nuestro cerebro y somos bastante reacios a aceptar un ordenamiento de ideas originadas en nuestro ambiente cultural, si bien estamos como esponjas absorbiendo aquéllas sancionadas por instancias que se nos han impueslo y aceptamos como dogmas.

Trabajamos con la racionalidad y la sensualidad al mismo tiempo. Por ello es bastante difícil dar una explicación exhaustiva de nuestro comportamiento y de los resultados de nuestro trabajo. La parte sensual de nuestra obra no puede ser explicada racionalmente, a no ser que pierda su sentido; una falta de explicación nos obliga a tomar partido por sí o por no sin más trámite, lo cual nos lleva al terreno del gusto, el cual es, como se sabe, tan movedizo como variado es el gustador, o al terreno de la ironía, que manejamos a la perfección, creemos, lo 
cual no es lo mismo que humor. En nuestra inhibición dejamos la ironía a los caricaturistas y nosotros adoptamos posturas a veces propias de caricatura.

Es difícil mantenernos en procesos de organización + seguimiento + reciclaje, lo cual para nada desecha inteligencia; es más bien el efeclo que produce en la sociedad la inestabilidad de la estruclura de los actores en la jerarquía (jefes que dan órdenes pero que no enseñan) o en el tiempo (jefes no permanentes $y$, por tanto, sin garantía del seguimiento de un proyecto). El reciclaje no se hace por sus elevados costos: un diseño se entrega con base en uná primera idea, quizá bien definida, quizá no. Respecto a la información, nos falta coordinación en nuestro trabajo en relación con las fuentes: me explico, el ingeniero debe utilizar los datos técnicos para su trabajo, no se le exige más pero se le exige eso. El arquilecto improvisa, creyéndose de ese modo creativo, o copia desaprensivamente. Entiéndase, copiar ha sido siempre parte de la creatividad en la civilización; pero lo importante es: interesa saber copiar con criterio. No tenemos o tenemos criterios desordenados para el diseño de una obra. Los resultados de todo esto son muy variados, pero identificables por lo que llamaría su lenguaje de feria (tomamos de todo un poco, como venga), lo cual nos conduce a la pregunta: ¿qué es, entonces, la arquitectura latinoamericana?

\subsection{Problemas especílicos de la producción de arquilectura}

Todos necesitamos conocer y poder atenernos a pautas. Este término corresponde a lo que se denominó en inglés pattern (Christopher Alexander) y que se tradujo por patrón. Considero esta palabra inadecuada y prefiero la española pauta, que tiene algo del lenguaje de la música, del ritmo, acento y colorido que corresponde más a un diseño creativo que a un acomodamiento según un catálogo de formas arquitectónicas, a programas no siempre alentadores para un diseño creativo, por ejemplo, un edificio de actividades culturales. Las pautas son siempre motivo de largas discusiones, pero para nuestro trabajo propongo usar aquéllas que más nos puedan ayudar: en primer lugar, pautas para lo existente y lo deseable. Ese mundo síquico tan delicado en nuestro medio con complejo de inferioridad. Pautas morales, sociales y antropológicas, en donde ubiquemos con acierto nuestros motivos, a veces inconscientes, de discriminación social; o, como dicen los sicólogos en un lenguaje difícil, la alteridad, el ser de otro modo.

Pautas para diseño propias para nuestras condiciones. Si bien la geografía física puede ser - junto con las condiciones del terreno- lo mismo en Puerto Madryn (Argentina) que en el Puerto de La Libertad (El Salvador, C.A.), no lo son ni el clima ni las condiciones de vida, ni las infraestructurales. Por eso aprendemos a mantener las distancias y ver las diferencias en casos de fuerte atracción hacia un proyecto que nos sugiera algo que no tenemos ni somos, por ejemplo, los habitantes de países nevados. Igualmente necesitamos códigos de edificación, por respeto a nuestros vecinos y a nuestras ciudades. Ese punto no puede quedar por último; 
en el futuro será necesario apoyar las iniciativas de los gremios que se decidan a iniciar —o continuar- una obra tan encomiable, sin que por eso nos hagamos sospechosos de burócratas. Aquí somos, sin duda, supersensibles.

Necesitamos pautas estélicas. Este tema nos produce una especie de vergüenza ajena, como si la belleza estuviera ahí y no fuese necesario hablar de ella. No es de ningún modo obvia, no está al alcance de la mano y cuesta muchísimo alcanzar en una obra la belleza soñada por el mismo diseñador. Esa calidad de sueño es positiva pero exige un manejo magistral de diseño arquitectónico. Estudio del delalle que es culminación de la idea.

Esto nos alentó a crear nuestras propias formas, tímidamente al comienzo, luego con una valentía y un entusiasmo que hasta hoy se mantiene. Clorindo Testa fue quien descubrió un lenguaje formal urbano en su Banco de Londres, para Buenos Aires, liberándose de la influencia de Le Corbusier, notoria aún en la mayoría de los arquitectos argentinos, como constata Ramón Gutiérrez (En torno a la dependencia y la identidad en la arquitectura iberoamericana). (Dado el interés que había despertado este tema y la inquietud de los estudiantes por una participación más activa en el proceso de análisis y formulación de ideas, en una de mis clases de Análisis Histórico en la UCA, la arquitecta Sandra Gutiémez, que hizo de instructora en ella, pidió que cada grupo hiciera referencia a los aspectos teóricos y críticos del autor Ramón Gutiérrez, en el citado artículo, y los relacionasen con algo que pudiera ser específico de El Salvador. Se exigía que se refirieran a aspectos arquitectónicos y urbanísticos, por lo cual se visitaron lugares de la ciudad de San Salvador, con ejemplos de arquitectura o urbanismo, que correspondían al terna elegido.)

Aunque estamos preocupados por nuestra identidad y nuestra realidad, cada uno está consciente de qué quiere y que cree que puede hacer algo. Ha costado mucho desechar de nosotros la apalía de este tipo de dependencia. Hoy podemos pensar - y no estaríamos lejos de la verdad- que cualquier arquilecto puede resolver un problema, siempre que to plantee bien. Nuestras condiciones son nuestra identidad. ¿Acaso no lo dice bien claramente para todos Denise Scott Brown: ¿el público debe ser escuchado'?

Podríamos recuperar nuestra identidad, quizá no en la forma exacta de la época colonial o de los centros intocados de las ciudades. Pero tuvimos un Carlos Raúl Villanueva, tenemos un Rogelio Salmona y también todos los demás. Los arquitectos resolvieron todos los problemas de los edificios; la fama de Niemeyer lo llevó a construir en Argelia la universidad de la ciudad de Constantine: cultura árabe, país africano, arquitectura brasileña influenciada por Le Corbusier. Internacionalismo. Las capacidades profesionales respectivas de las arquitectas Teolinda Bolívar (venezolana), Silvia Arango (colombiana), Marina Waisman (argentina) y otras autoridades en la crítica de la arquitectura y el urbanismo están ayudándonos a todos. La obra teórica y la investigación son parte del diseño, 
que ayudan al deseo de crear algo nuevo como impulso. En esa investigación estamos descubriendo; actuar a continuación es algo humano y por ello siempre nuestra profesión será acción. Que sea acción consciente.

\section{Las influencias culturales: europea, norteamericana y otras}

En América Latina, los arquitectos recibieron todas esas influencias con fervor de iniciados y no hubo más oídos para las recomendaciones de una arquitectura propia. La realidad era que nuestra identidad hispánica no resolvía ningún problema más que algún prurito elegante o nostálgico, y la verdadera corriente era esa fuerza que nos absorbía a todos y nos unía en un trabajo modemo y dinámico. No creo, además, que hubiéramos podido convencer a los inversionistas con algún proyecto caro por su generosidad de espacio, su lujo de formas o su misterio de mensaje. El funcionalismo no era una filosofía, era un procedimiento para hacer rendir el capital. Pero se hizo universal y los países socialistas no lo negaron, y lo adoptaron frente a la pésima arquitectura del realismo soviélico.

Lo que los arquitectos latinoamericanos aprovechan de la gran reserva que significa para el mundo el quehacer arquitectónico europeo y norteamericano, está relacionado con la capacidad crítica de las sociedades donde esos arquitectos deben actuar. Esto se ve claramente en el caso de Brasil, cuya producción se destacó notoriamente de las otras en el continente por su lenguaje propio y la relación de algunas obras con el tejido urbano en general.

En América Latina encontraremos que la influencia es mayor en los sectores de la clase dominante, sean banqueros, industriales o militares, para quienes la formación de una esquemática idea de la grandeza nacional y del progreso económico se liga indisolublemente a la propia astucia para entrar en la estrategia global de los grandes países. Incluso en ese particular, Cuba es la excepción. Pero ese aspecto político es bien conocido y no se desarrollará aquí. Lo que más me preocupa es en qué medida estamos en condiciones de relacionar nuestras necesidades de hábital y ciudad con nuestra capacidad profesional para satisfacerlas. Esto podría ser larea de la formación técnica, pero igualmente podría corresponder a una sección de la teoría del conocimiento; es indudablemente un problema intelectual y debemos insistir en ello.

En su libro Las bellas apariencias, una crífica arquitectónica (Schöner Schein, eine Architekturkrifik), su autor, Michael Müller, intenta una visión actual de lo que fue la arquitectura del modernismo. Plantea las tesis de la vanguardia (Otto Wagner, entre otros) y relee un texto que es de conocimiento público entre los arquitectos europeos:

"La visión de [Otto] Wagner respeclo a la arquitectura moderna, consiste en que el arquitecto deberá lograr darle a cada paso del desarrollo social y con las formas apropiadas, la dimensión de modernidad" (Müller, 1987, p. 90) La pregunta es si Wagner vio eso en su proyecto ideal, bastante versallesco, para el 
distrito XXII de su ciudad, Viena, hecho en 1910-11. Por cierto, los textos que cita Müller se refieren a la frase inicial de Loos: "El ornamento debe prohibirse". Relacionemos esta frase con dos ejemplos.

(1) Carlos Raúl Villanueva y su obra maestra El Silencio. Sucede con este proyeclo que pasó desapercibido por la crítica intemacional. Se ha iniciado una revisión de texlos que entre nosotros no fueron tenidos en cuenta ni siquiera cuando aparecieron. Es muy difícil encontrar una justificación del diseño de $E l$ Silencio, salvo la del propio Carlos Raúl Villanueva. Aquí correspondería dilucidar si Villanueva fue vanguardista o si fue un ecléctico más. Para la escenografía urbana, El Silencio es vanguardista si tenemos en cuenta que no existe ningún otro ejemplo en América Latina de diseño con preocupaciones estéticas de identidad cultural en la vivienda popular latinoamericana. Y el detalle no está sólo en el lenguaje - la columna panzuda- está más bien en la escala: es un barrio, no es un complejo ni una serie de bloques. Hay que esperar a Hertzberger en Holanda (1980) para encontrar el mismo concepto de hábitat. Ya es algo de mérilo.

(2) Lucio Costa: Brasilia, los comentarios brasileños sobre el proyecto son más de carácter sicopolítico que arquiteclónico o urbanístico, aunque en este sentido las críticas sobre la estética urbana de Brasilia también fueron a veces muy duras. Actualmente y a partir de Segre, Brasilia es altamente cuestionada, y con razón, por su desarrollo absurdamente especulativo y alejado del proyecto original. Sin embargo, sigue siendo el único producto latinoamericano de nivel internacional en el campo de la composición urbanística. ¿Qué pasa? Brasilia es un monumento y no una ciudad. Porque el gran desfasaje que daña al diseño se produce en la falta de relación entre el usuario y el arquitecto como seres constructores $\mathrm{y}$ artistas. Todos tenemos una cierta conciencia de lo bello $\mathrm{y}$ mucho de la realidad de la necesidad para poder decir que siempre hay algo de artista y de artesano en cada uno de nosotros. El Homo Faber, de Huizinga.

Estamos necesitados de relacionar más el aspecto no expresado de nuestra vida en el hábitat de todos y el aclo de conformar ese hábilo. Si fuese una verdad ya sabida, como la cultura habilacional de los africanos o de los tibetanos, no necesitaríamos analizar nuestro entorno. Si fuésemos tan antiguos en nuestra civilización como los orientales, no haríamos sino escribir versos a la naturaleza. Pero somos una sociedad nacida de condiciones de dependencia cultural, lo cual no quiere decir necesariamente que cada de uno de nosotros se considere dependiente en ese sentido o cómo se considere dependiente.

Lo que se produce es un choque entre ser y no ser dependiente. La cultura dominante no es absorbida y reelaborada (como han hecho los europeos después del avasallador influjo que ejercieron en ellos los norteamericanos en la segunda postguerra mundial, para lo cual indudablemente ya tenía una práctica de dos milenios), sino que es asumida o rechazada en bloque. Pero si se quiere elaborar 
no hay tiempo, medios u oportunidad. Tal fue el caso de Ciudad Guayana en Venezuela, proyectada por el alemán W. v. Moltke y construida por técnicos norteamericanos con el petróleo venezolano.

Ver la arquitectura exige un aprendizaje, como lo propuso Bruno Zevi en su aleccionador Saber ver la Arquitectura. Recopiladores como Marina Waisman (diversas publicaciones), Damián Bayón y Paolo Gasparini (Panorámica de la arquirectura Latinoamericana), Jorge Liernur (América Latina, arquitectura, los últimos veinte años), Cristián Boza (diversas publicaciones), Silvia Arango (Historia de la Arquitectura Latinoamericana), Aracy Amaral (Arquitectura Neocolonial) y muchos otros nos ofrecen información y análisis. $Y$ además, está la crítica.

Roberto Segre, después de realizar una inmensa labor analítica de la obra cubana, se interesa por el impacto que va a producir en la capital cubana la obra posmoderna de los jóvenes arquitectos, músicos, poetas, cineastas, obreros, etc. Liemur analiza la influencia que ha tenido la revolución cubana pero también la del Team X. Creemos que eso añade una nueva perspectiva a la teoría de la arquitectura en nuestro continente. El pensamiento urbano articula en un proceso de síntesis imprescindible los elementos encontrados en el análisis. Las conclusiones nos permiten reciclar. El pensamiento arquitectónico académico y profesional latinoamericano - y su correspondiente práctica - tiene en la inmensa mayoría de los casos durante el siglo $\mathrm{XX}$ un constante ingrediente norteamericano. La modernidad latinoamericana no es sólo europea, también tiene sus influencias de Eslados Unidos. Más aún, el cosmopolitismo de la arquitectura de las metrópolis latinoamericanas ha sido mencionado pero no considerado un objeto de estudio. Al respecto hay un artículo muy interesante del arquitecto argentino Juan Carlos Pérgolis, profesor en Colombia, El europeísmo en la arquilectura latinoamericana.

La razón está en nuestra problemática sicosocial, como mencioné al comienzo. Relacionar estilos y comportamientos, tecnologías y sistemas de producción en un conjunto nos produce problemas. Sin embargo, la convivencia de la alta tecnología, el comportamiento anónimo del individuo metropolitano y el inmenso aporte cultural recibido en las grandes ciudades, se codea con las artesanías, el espíritu del lugar y la cultura tradicional/local. En ese campo hemos hecho y seguiremos haciendo arquitectura y urbanismo. Si el arquitecto argentino-francés Noël descolló a principios del XX en el manejo del estilo neocolonial, Buschiazzo conocía a fondo el racionalismo; en Brasil, Niemeyer competía con la bella formulación de la arquitectura neocolonial; Bahla presentaba un ideal urbano tan fuerte como Río de Janeiro pero con un acervo cultural opuesto: tradicional, no aluvional.

En las ciudades menores del continente hubo algún arquitecto seguidor de Wright (Nechodoma en Sanlo Domingo, Carlos David en Córdoba). Estudiamos 
profundamente a Neutra, Mies van der Rohe. Saarinen, consagrado por las formas de doble curvatura de Idlewild, nos era tan presente como Félix Candela de México por su obra técnico artística. Hoy son fundamentales Santiago Calatrava y Frank $O$. Gehry. Pero quizá no sea sólo la parte consagrada de los arquitectos lo que nos da una línea de continuidad: también son los elementos de la modemidad en su conjunto: la fascinación del producto norteamericano, algo como un fetiche de democracia. La refrigeradora, las líneas aerodinámicas, la pureza de la línea no interrumpida por la decoración — la exigencia de Loos.

Sería muy interesante seguirle el rastro a alguna idea semejante en nuestro acervo cultural, algo como estoicismo, sencillez, algo más de todos los días, dicho por mucha gente: "me gusta porque es sencillo"; el ser nuestro intelectual heredero de un deseo además de una carga sicológica: ser moderno. Uno de los que interpretó con absoluto rigor esa fórmula fue el arquitecto argentino Wladimiro Acosta. En los cincuenta tomó las ideas de los racionalistas europeos, Le Corbusier (suizofrancés), Hilberseimer (alemán), Loos (austriaco) y desarrolló un esquema para la arquitectura urbana.

Sin embargo, riqueza se asimila a modemidad, no a tradición; el riesgo se corre, la cultura resulta alienada, pero los beneficios son innegables: confort, música de jazz, ilusión. El arquitecto usa el lápiz creyéndose un Mies, un Gropius, un Salmona o un Calatrava. Los exégetas no escriben ni hablan, usan el lápiz, seguros, individualistas. Quizá porque somos una cultura demasiado (?) joven. Basta de narcisismo. Y cito a Germán Téllez: "Viva y trabaje en teoría. En el mundo de la teoría nadie paga impuesto, y no se ama ni se odia. Pero se toca arpa..."

\section{El estado de la teoría}

Este punto está disociado de la realidad y por eso no nos permite damos cuenta de si avanzamos o no. Para localizar el problema existen muchos elementos (bibliografía además) y es necesario guiamos por un esquema, por una idea: la arquitectura latinoamericana existe, si se puede decir, por el sólo hecho de que existen edificaciones. Esta aseveración es aparentemente antiacadémica y también incómoda, pues sentimos que nos obliga a sacudimos de encima la cansada y repetida frase: no tenemos arquitectura propia. Porque parece ser más cómodo decir eslo que aceptar toda la construcción existente - la cual tendría que ser como el objeto central de nuestra observación, investigación, clasificación, evaluación, etc. Estoy, pues, molestando con lo que digo, quitándole a los lugares comunes de la autocrítica su base cómoda, nihilista. Sin embargo, voy a seguir molestando; voy a trabajar la frase: edificaciones como base de teoría:

La teorización empezaría por lo antropológico: si buscamos la identidad de la arquitectura, nos parece imprescindible ubicar a ésta dentro de la cultura y no aislarla como un producto aséptico. Cuando los teóricos de la talla de Tafuri 
discuten sobre arquitectura, lo hacen en absoluto convencimiento de que ésta pertenece a la cultura. Está involucrada en el conjunto de la cultura.

¿Cuál es nuestra cultura? Porque alienados o no, la tenemos. Ignorándola no la vamos a poder analizar: origen, modificación, proyección, retroalimentación, recomienzo es el ciclo. Una negación rotunda y perniciosa de ese ciclo imprescindible para consolidar la cultura aparece en el afrentoso libro El Asco, de un autor salvadoreño: al negar la existencia de una cultura y reemplazarla por un cuadro suicida de su propia personalidad, su autor nos provoca la necesidad de protestar. Como yo supongo que él tuvo la mejor intención al escribir ese insulto globalizador a su pais, me provoca decir que la mejor protesta es el estudio, el profundizar en las razones de un semejante escapismo. Pues cultura e investigación son manifestaciones de responsabilidad social. Y ese ciclo existe: está en cada actividad, Homo faber cada casa que se consiruye. Y está también en la satisfacción de haberla construido por modesta que sea, Homo ludens.

En el tema de la antropología de la casa hay documentación exhaustiva de que toda mujer, todo hombre produce un espacio, su espacio y lo convierte en su lugar para habitar. Que no reconozcamos eso como arquitectura es un error nuestro, de los arquitectos y de los intelectuales. (Y no es, además, una verdad absoluta que todos los arquitectos e intelectuales lo nieguen y lo ignoren.)

Si no queremos seguir moviéndonos en el nivel de una superficialidad tal que desprecie todo contenido y nos imposibilite todo juicio sobre nuestra propia obra, debemos hacer coincidir la necesidad con el resultado: esta simple fórmula origina una obra, empezando por la remoción de la tierra y terminando por la última frase de satisfacción - si llega algún día- cuando la vivienda está terminada. Homo Faber es una expresión aplicable a todo sujeto y, por ende, toda obra es analizable. La organización de un espacio es aprehensible por la acción, posteriormente por el uso, y, finalmente, por la contemplación hasta de los extraños. En esa relación activa de construir algo que cumple un fin -construir una habitación para abrigarse- está la arquitectura; y es más: construir significa pensar en reunir materiales, movimientos, esfuerzos; significa usar técnicas apropiadas, lograr resultados efectivos y precisos, significa abstraer, llegar a lo que debe ser entre todas las cosas que podrían ser; significa planificar previamente, como comprobación de la ventaja de la planificación después de haber probado y perdido demasiado (materiales, esfuerzos, tiempo) en la prueba y el enror; significa aceplar los conocimientos anteriores; los cánones, las reglas, las nomas, explícitas o lácitas de la sociedad.

Planificar significa conocer el sentido de lo que estoy haciendo, para quién. Significa reconocer la sociedad en la que vivo y no el gobiemo, el país y no el Estado. Por eso la crítica a una arquitectura -cualquiera que sea- es tan compleja. Si a priori no se le reconoce valor de arquitectura a alguna construcción, no se cree necesario aplicar tanto cuidado a su crítica. Faltó el análisis, o el 
profundamente a Neutra, Mies van der Rohe. Saarinen, consagrado por las formas de doble curvatura de Idlewild, nos era tan presente como Félix Candela de México por su obra técnico artística. Hoy son fundamentales Santiago Calatrava y Frank $O$. Gehry. Pero quizá no sea sólo la parte consagrada de los arquitectos lo que nos da una línea de continuidad: también son los elementos de la modernidad en su conjunto: la fascinación del producto norteamericano, algo como un fetiche de democracia. La refrigeradora, las líneas aerodinámicas, la pureza de la línea no interrumpida por la decoración - la exigencia de Loos.

Sería muy interesante seguirle el rastro a alguna idea semejante en nuestro acervo cultural, algo como estoicismo, sencillez, algo más de todos los días, dicho por mucha gente: "me gusta porque es sencillo"; el ser nuestro intelectual heredero de un deseo además de una carga sicológica: ser moderno. Uno de los que interpretó con absoluto rigor esa fórmula fue el arquitecto argentino Wladimiro Acosta. En los cincuenta tomó las ideas de los racionalistas europeos, Le Corbusier (suizofrancés), Hilberseimer (alemán), Loos (austriaco) y desarrolló un esquema para la arquitectura urbana.

Sin embargo, riqueza se asimila a modemidad, no a tradición; el riesgo se corre, la cultura resulta alienada, pero los beneficios son innegables: confort, música de jazz, ilusión. El arquitecto usa el lápiz creyéndose un Mies, un Gropius, un Salmona o un Calatrava. Los exégetas no escriben ni hablan, usan el lápiz, seguros, individualistas. Quizá porque somos una cultura demasiado (?) joven. Basta de narcisismo. Y cito a Germán Téllez: "Viva y trabaje en teoría. En el mundo de la teoría nadie paga impuesto, y no se ama ni se odia. Pero se toca arpa..."

\section{El estado de la teoría}

Este punto está disociado de la realidad y por eso no nos permite darnos cuenta de si avanzamos o no. Para localizar el problema existen muchos elementos (bibliografía además) y es necesario guiarnos por un esquema, por una idea: la arquitectura latinoamericana existe, si se puede decir, por el sólo hecho de que existen edificaciones. Esla aseveración es aparentemente antiacadémica y también incómoda, pues sentimos que nos obliga a sacudimos de encima la cansada y repetida frase: no tenemos arquitectura propia. Porque parece ser más cómodo decir esto que aceptar toda la construcción existente - la cual tendría que ser como el objeto central de nuestra observación, investigación, clasificación, evaluación, etc. Estoy, pues, molestando con lo que digo, quitándole a los lugares comunes de la autocrítica su base cómoda, nihilista. Sin embargo, voy a seguir molestando; voy a trabajar la frase: edificaciones como base de teoria:

La teorización empezaría por lo antropológico: si buscamos la identidad de la arquitectura, nos parece imprescindible ubicar a ésta dentro de la cultura y no aislarla como un producto aséptico. Cuando los teóricos de la talla de Tafuri 
discuten sobrc arquitectura, lo hacen en absoluto convencimiento de que ésta pertenece a la cultura. Está involucrada en el conjunto de la cultura.

¿Cuál es nuestra cultura? Porque alienados o no, la tenemos. Ignorándola no la vamos a poder analizar: origen, modificación, proyección, retroalimenlación, recomienzo es el ciclo. Una negación rotunda y perniciosa de ese ciclo imprescindible para consolidar la cultura aparece en el afrentoso libro $E l$ Asco, de un autor salvadoreño: al negar la existencia de una cultura y reemplazarla por un cuadro suicida de su propia personalidad, su autor nos provoca la necesidad de protestar. Como yo supongo que él tuvo la mejor intención al escribir ese insulto globalizador a su país, me provoca decir que la mejor protesta es el estudio, el profundizar en las razones de un semejante escapismo. Pues cultura $e$ investigación son manifestaciones de responsabilidad social. Y ese ciclo existe: está en cada actividad, Homo faber cada casa que se construye. Y está también en la satisfacción de haberla construido por modesta que sea, Homo ludens.

En el tema de la antropología de la casa hay documentación exhaustiva de que toda mujer, todo hombre produce un espacio, su espacio y lo convierte en su lugar para habilar. Que no reconozcamos eso como arquitectura es un error nuestro, de los arquitectos y de los intelectuales. ( $Y$ no es, además, una verdad absoluta que todos los arquitectos e intelecluales lo nieguen y lo ignoren.)

Si no queremos seguir moviéndonos en el nivel de una superficialidad tal que desprecie todo contenido y nos imposibilite todo juicio sobre nuestra propia obra, debemos hacer coincidir la necesidad con el resultado: esta simple fórmula origina una obra, empezando por la remoción de la tierra y terminando por la última frase de satisfacción - si llega algún día - cuando la vivienda está terminada. Homo Faber es una expresión aplicable a todo sujelo y, por ende, toda obra es analizable. La organización de un espacio es aprehensible por la acción, posteriormente por el uso, y, finalmente, por la contemplación hasta de los exIraños. En esa relación activa de construir algo que cumple un fin -construir una habitación para abrigarse- está la arquitectura; y es más: construir significa pensar en reunir materiales, movimientos, esfuerzos; significa usar técnicas apropiadas, lograr resultados efectivos y precisos, significa absiraer, llegar a lo que debe ser entre todas las cosas que podrían ser; significa planificar previamente, como comprobación de la ventaja de la planificación después de haber probado y perdido demasiado (materiales, esfuerzos, liempo) en la prueba y el error; significa aceplar los conocimientos anteriores; los cánones, las reglas, las normas, explícitas o tácitas de la sociedad.

Planificar significa conocer el sentido de lo que estoy haciendo, para quién. Significa reconocer la sociedad en la que vivo y no el gobierno, el país y no el Estado. Por eso la crítica a una arquitectura -cualquiera que sea- es tan compleja. Si a priori no se le reconoce valor de arquiteclura a alguna construcción, no se cree necesario aplicar tanto cuidado a su crílica. Faltó el análisis, o el 
crítico se refugió en un análisis cuantitativo. Entre ciertos arquitectos es un argumento manido que socialmente nos debemos a una sociedad pobre; por eso, se supone, podemos ahorrarnos todas las discusiones complejas respecto a la génesis del espacio arquitectónico pobre. Pero sucede que la sociedad avanzada no tiene inconveniente en analizar situaciones arquitectónicas (espacio, lugar) de baja calidad, como consecuencia de crasa injusticia. Si esto queda claro, no se trata sólo de denunciar la inhumanidad de un tugurio, sino de cuándo los arquitectos se van a ocupar de estudiar el espacio de la arquitectura pobre.

Mi opinión es que todo lo que decimos de un proceso de creación y construcción de un lugar es válido programáticamente; lo que varía es el objetivo. Observación, clasificación y juicio conforman un conjunto de funciones propias de la mente humana, desde el niño hasta el anciano sin excluir al dernente ni al discapacitado. El resultado de las decisiones de cada una de las personas es un aporte a la cultura de la sociedad de esas personas. Ese gran edificio de decisiones se acumuló y se seguirá acumulando en todos los momentos en las sociedades humanas. Su justificación se hará dentro de los márgenes posibles, su trascendencia dependerá de los márgenes, de su amplitud y de su coherencia. su validez será coyuntural y seguirá procesos históricos, los que a su vez generarán nuevas corrientes. Este es un circuilo suficientemente sencillo y almacenable en un buen programa de compulación aplicable a la más simple o la más complicada de las computadoras. La lógica de los pasos se comprueba a cada momento en la continuidad del funcionamiento del programa y del sistema. El todo se llama Historia. Es necesario que seamos capaces de enseñar así nuestra historia.

En diferentes cursos y en distintos lugares, mis colegas y yo hemos estado tratando de localizar la tarea del arquitecto en estos tiempos. Una de las preocupaciones fue investigar sobre lo específico que le compete al arquilecto, lo específico de ser arquileclo. No hay duda que la diversidad de siluaciones sociales en América Latina ha convulsionado los espíritus, y muchos arquitectos han incorporado diferentes disciplinas afines a lo urbano y lo construido en su quehacer. Posiblemente hayan cuestionado la arquitectura sola, aislada de aquel compromiso. De acuerdo, sin embargo, existe el compromiso de aprender a hacer arquitectura y es por eso que estamos pensando todo esto.

\subsection{Regionalismo: geometría y lugar}

Ahora quiero concentrarme en lo que se disculió en diversas oporlunidades. ¿Cómo se identifica la arquitectura? ¿Cómo se produce? Doy una respuesta tentativa: por la combinación de geometría y lugar. $\mathrm{Y}$ ahora hay que demosIrarlo. Empecemos por la geometría en la arquitectura. Formulado así es confuso, por tanto, voy a extenderme. Se dijo que la modernidad - y su correlato más preciso, la arquitectura racionalista- había sido innovadora y después dogmática en el uso de la geomelría: cubo, esfera, pirámide. El conceplo múltiple de 
plano, línea y punto había preocupado fundamentalmente a los teóricos de lo formal racionalista.

Veamos en qué medida este material podría ser válido para nuestra uso de la geometría en la arquitectura. El posmodemo extiende el concepto de geometría simple a una más compleja. Existe una ilimitada variedad de combinaciones de poliedros usados por el posmoderno, aparte de otros cuerpos. En cuanto a los poliedros, el arquitecto Eisenmann parte del cubo vaciado y lo interseca con otro cubo vaciado y produce planos entre las aristas; llena después a voluntad ciertos planos resultantes con elementos de todo tipo y así ofrece una nueva sensación de espacio. Según Jencks, esa experiencia coincide con la esencia formalista del posmodemo.

Y después de haber logrado confundir al lector con la geometría vamos al lugar. Surge la correspondiente pregunta del teórico investigador para la práctica arquitectónica: ¿en qué lugar sucede esto? Y me parece que la respuesta está, en parte, en la tesis de Salmona sobre las condiciones del lugar.

Si unimos la geometría postmoderna al conceplo lugar, algo diferente va a resultar. Quiero decir, ya no se trata de la fómmula universal racionalista: la misma forma para cualquier lugar, sino que se reemplaza por la nueva altamente flexible: cada forma surge de un lugar. Es una aseveración arriesgada, como lo dernuestra el regionalismo posmoderno. Pero es un instrumento de trabajo que tiene dos ventajas esenciales: (a) maneja realidades, siendo éstas determinantes para la obra arquitectónica; y (b) convalida sólo aquellas formas que surgen del lugar.

Esta vía de análisis, o, para no ser tan abstractos, de observación, nos permite mirar las producciones regionales con un criterio orientador. Se trata de ver si la correspondencia al lugar se mantiene. ¿Podría ser un ejemplo la famosa capiIla de Ronchamp, de Le Corbusier, con lo cual el arquitecto veneciano Alberto Fabrín, alumno de Tafuri, tendría razón al decir que Le Corbusier fue el primer posmoderno? Podría ser un ejemplo válido, aunque no es necesario insistir sobre la etiqueta. Le Corbusier era más que un posmodemo o un moderno. Era un creador auténtico y, en ese sentido, universal y atemporal.

Esto da motivo a una ampliación teórica: el posmoderno también es consciente del lugar. De ello se habían encargado autores de la talla de Gordon Cullen, Kevin Lynch, Norberg Schulz y el español Muntañola; otros menos conocidos pero no menos importantes, como el arquitecto español Carlos Flores, quien investigó precisamente la arquitectura regional de su país, obligado texto de consulta: Tal es la esencia de la expresión genius loci. Por lo que sé, Flores realiza en el mundo la primera tarea de sistematización de la arquilectura regional de un país, con su espíritu del lugar, con lo cual va más allá que una simple guía turística. El genius loci, espiritu del lugar, se convirtió en la expresión (de 
Norberg Schulz) intelectualizada de un acontecer diario para cada cual. La sensación de saber que este lugar algo me dice. Olvidado entre los impulsos de un modemismo acrítico, los conceptos de lugar y regionalismo se habían reservado para los históricos, los sociólogos y los escenógrafos de películas concientizadoras. Hoy se produce, por suerte, un renacimiento de la idea en varios programas de televisión.

Una recuperación del espíritu del lugar la iniciaron los arquilectos de las ciudades del viejo continente europeo. Encargados por las alcaldías o por grupos de usuarios de una tarea concreta, cual fue ver cuánto tiempo podrían seguir usándose las viejas construcciones de vivienda, se pusieron a investigar sobre métodos de rehabilitación edilicia y fueron viendo lo que tenían delante de sus ojos y le alribuyeron un valor nuevo. Muchas obras se han realizado en el sentido de recuperar viejas construcciones y crear un espíritu del lugar acorde con los nuevos tiempos, y algunos de estos trabajos ostentan una geometría postmoderna altamente aceptable. De todo lo anterior se deduce una tarea para nosolros, arquilectos latinoamericanos: asistir a los investigadores en sociología urbana en todo lo específico de sus disciplinas, con nuestro instrumental arquitectónico, y pensar cómo podemos recuperar nuestra propia capacidad de ver los elementos formales de nuestras ciudades y ganarlos para la arquitectura.

Creo que ello es difícil por dos cosas: porque tenemos que quitamos un velo de modemismo acrítico y encontrar en aquéllo que veamos el contenido arquitectónico adecuado. Eso nos obliga a formamos nuestro propio sistema de comunicación, lenguaje, símbolos, hipótesis, formas, etc. Todo ello incluye el aprendizaje que hagamos de la arquitectura popular y/o social promovida por las nuevas tendencias sociales: arquitectura popular participativa (barrio Petare en Caracas); políticas de rehabilitación barrial (El Agustino, Lima), Urbanizaciones Progresivas en Managua, agrupaciones de usuarios para la rehabilitación de sus viviendas (microbrigadas, La Habana); juntas de vecinos, activistas de centros urbanos deteriorados (La Pintada, Santiago de Chile); inquilinos en acción de rehabilitación de su hábitat (Montevideo y Buenos Aires); programas de investigación en rehabilitación de tugurios y mesones (Fundasal, San Salvador; C.E.V.E., Córdoba, Argentina; Ciudad, Quito).

Para ello debemos reforzar en los estudios universitarios nuestra capacidad didáctica a través de varios pasos: $(a)$ ver, observando y replicando, o sea, haciendo dibujos copiados, calcados, como sea, de los trabajos que vemos, ya que es importante trascender el facilismo de la folocopia u otro método artificial, lo cual no niega el uso de la compuladora pero después de haber pensado; (b) ordenar lo visto en un acervo cultural propio, que puede ser un sistema, un esquema, una estructura o lo que se quiera; es importante asumirse como intelectual en tanto arquitecto y no como mero cazador de formas casi siempre furtivas, aunque siempre atrayentes; (c) aprender a ubicarse en la realidad en que 
se vaya a trabajar, independientemente del compromiso social, que nadie puede prescribir a nadie en el terreno de la arquitectura, pero sí tratar de encontrar la arquitectura que coincida con el compromiso social que cada uno asume. Con esto quiero decir que asumamos la tarea esencial de la autenticidad de nuestra arquitectura.

\subsection{De la teoría a la práctica y viceversa}

Jorge Glusberg publicó en la revista chilena de arquiteclura ARS (julio, 1984, pp. 122-3) un artículo tilulado "Acerca de las relaciones entre la leoría y la práctica". Primera cuestión: "saber en qué medida el discurso acerca de la arquitectura influye sobre lo que efectivamente se edifica; es decir, cómo se produce la relación inversa, no de lo construido a su teoría, sino de la teoría a la práctica arquitectónica". Sin tratar a fondo la cuestión, Glusberg justifica la crítica de alguien que no es arquitecto. Otra cuestión: "el hábitat no es algo ajeno al sujeto; es algo vivido íntimamente por él, y aunque no lo haya construido lo incorpora desde los años más tempranos de su infancia". El autor justifica más extensamente la labor del escritor no necesariamente arquitecto en la teorización de la arquitectura, "así el reflejo de la teoría en la práctica no sólo es posible sino necesario en muchos casos. Sin elementos que marquen pautas de acción a partir de ciertos principios y ciertos fines, el arquitecto actuaría a ciegas y su formación se reduciría a aspectos exclusivamente técnicos". Son conceptos válidos, aunque quizá todavía demasiado generales para poder arrancar de allí con una epistemología de la crílica, tal como en la entrevista Wolfe-Eisenmann. Realmente quisiéramos saber si nuestra sociedad está tan distante de la europea como para afirmar que no tenemos clase media en el sentido que Wolfe la concibe. Creo que sí la tenemos y que - a diferencia de Estados Unidos - somos, en algún sentido, mucho más europeos que ellos; aunque en otros aspectos nos alejamos bastante. Esta sería para mí una cuestión por analizar: ¿es posible hacer arquitectura para un grupo social desconocido por el arquitecto? Voy a volver sobre el punto.

"El punto inverso", sigue Glusberg, "o sea, en qué medida lo construido determina el conjunto de teorías de la arquitectura, no es superfluo". Lo que sí parece demasiado vago es el discurso sobre la relación entre teoría y práctica a partir del edificio construido, y poco ayuda a nuestra aproximación "la necesidad de tener instancias que lo sustenten en forma adecuada". Creo que lo que quiere decir Glusberg es casi obvio: se trata de tener más publicaciones que se dediquen a analizar las obras construidas desde puntos de vista teóricos, obras que por ser muchas "aunque se reduzcan al mínimo, desde el punto de vista de una topología sistemática de la arquitectura, dificultan la tarea del teórico".

En 1984, Glusberg fue a Hamburgo y evidentemente expuso esto con la intención de crear su Instituto. En él invesligaría para responder a esas pregun- 
tas. Está bien, nada en contra, Zevi tenía el suyo y nos hizo bien a todos. Lo que pasa es que hasta ahora no sé qué valor le asigna el autor a la arquitectura como disciplina profesional. Decidido admirador de Miguel Angel Roca, el representante del posmodemo en Argentina se estaría refiriendo a él. Claro que esa es mi suposición. Como no me pude quedar sin opinión respecto a esta verdad a medias sobre el quehacer profesional del arquilecto, busqué. Por suerte tengo un cuademillo, El Silencio y sus alrededores; en él leo el artículo de Lezsek Zawisza titulado "El Silencio: Arquitectura y Urbanismo". Carlos Raúl Villanueva conocía bien la obra de la Viena Roja, y en especial el Carl-Marx-Hof, de donde tomó la lipología de patios para su obra. Según Sibyl Moholy Nagy, en su obra Carlos Raúl Villanueva y la arquitectura de Venezuela (Caracas, 1964), "Villanueva debió aportar soluciones inéditas porque los problemas que enfrentaba carecían de precedentes". Básicamente se trataba de la vivienda para un sector del pericentro tugurizado de Caracas no atendido hasta ese momento y que ocasionaba problemas a la población vecina, que era más acomodada.

Vamos a observar con la lupa. Zawisza, al hablar de los jardines internos dice: "Para Villanueva estos espacios inlemos tenian un particular significado social y cultural, enfatizado en uno de sus comentarios: «El elemento básico del plan -escribia_, es decir, el elemento vivo que destaca el rasgo social de la concepción —el patio- ha sido trazado libremenle, con una sucesión de terrazas, verdaderas plataformas donde trabajan madres de familia, desde donde puedan ponerse en comunicación con hijos y vecinos. Eslos mismos patios hacen recordar algunos patios coloniales desorbitantes de vida, de esta vida latina que distinguirá durante largo liempo todavía a nuestros países de la América del Sur". (C. R. Villanueva, Caracas de ayer y de hoy.)

La explicación y justificación de cada una de sus decisiones es una clase magistral. Para terminar el comentario siguiente: “... el carácter histórico no quita valor al lado opuesto [hacia el Parque El Calvario, F.L.] de los Bloques que se desenvuelve entre las formas estrictamente rectilíneas y cúbicas de las terrazas, creando un eficiente juego de claroscuro, visto a través de los jardines".

Los historiadores o críticos no valorizaron suficientemente el período ecléctico de Villanueva y, para algunos de ellos, esta etapa parece ser una mancha en la reputación del más grande maestro de la arquileclura modema venezolana. Consideran que sus obras eclécticas correspondían a una "táclica cultural", es decir, al ofrecimiento de un producto aceptable al público venezolano, según el gusto que este público poseía. Esta tesis se apoya sobre la aseveración de que "la arquitectura modema nació de distintas condiciones económicas, sociales y culturales, bajo el impacto respectivo de la industrialización masiva..." Tal actitud crítica está hoy - para Zawisza - fuera de tiempo y lugar. Y aquí la propia opinión de Villanueva: "En lo que concieme al estilo propiamente dicho, consideré que era necesario hallar un enlace con la ciudad colonial, la cual tiende a 
perder cada día más su lípico carácter antiguo y recordar algunos elementos de su arquitectura básica".

Y Lezsek continua estableciendo un paralelo que nos conviene mucho leer: "Por el mismo sendero de las formas tradicionales y luego del modernismo con acento clásico, transitaron también olros arquitectos de renombre mundial, aproximadamente en la misma época. El hecho de que la "conversión» definitiva al diseño moderno, o lo que en 1930-40 se consideraba como modemo, es decir, el de la vanguardia arquiteclónica europea, era más temprana en algunos casos que en otros, se debía a varias razones circunstanciales y personales. Villanueva, un arquitecto formado en la escuela académica francesa, empieza a descubrir en los años treinta a su propio país, que en realidad era para él directamente desconocido. Sus experiencias le producen reflexiones acerca de la cultura nacional vista con la óptica de un arquitecto. Justo en la época cuando proyectaba $E l$ Silencio, paseaba por Caracas con la precisa tarea de fotografiar vistas de los portales barrocos, todavía abundanles entonces en la ciudad, como preciosos testimonios de las tradiciones en vías de desaparición. Está claro que en la mente del Maestro estaba presente no sólo la problemática de la arquitectura moderna, sino también la de la arquitectura nacional, ambas difícilmente compatibles".

Sobre esta posible compatibilidad escribe Leszek: "Dentro de esta óptica Villanueva "adopta resueltamente» la arcada y la decoración alrededor de las entradas en los Bloques. No para alabar el gusto momentáneo del público inculto, sino para crear, por encima de las preocupaciones puristas, un enlace con la ciudad tradicional. La intensidad con la cual utiliza en estos casos el repertorio ecléctico es desde luego variable. Podría, por ejemplo, optar por un pórtico con simples pilastras de sección circular o cuadrada y arquitrabes, en lugar de las columnas "panzudas» $y$ arcos, aunque tal solución restaría algo de la eficiencia del diseño finalmente adoptado, ya que Villanueva evidentemente insistía en su punto de vista, asumiendo una actitud casi desafiante". "Con igual valor decide contraponer a los frentes enriquecidos con pórticos y detalles neocoloniales, tomados de las casas de San Carlos y de Coro, el diseño totalmente moderno de las fachadas hacia los patios". Encuentra, además, puntos comunes entre la arquitectura moderna y la de nuestro pasado, escribiendo que "las paredes superiores de las arcadas están tratadas con la simplicidad de las grandes superficies planas de nuestra época colonial, que en mi opinión deben hoy señalar la arquitectura moderna".

Antes de hacer mis propios comentarios - por suerte en Caracas tuve dos oportunidades para ver la obra y, en compañía de una arquitecta, tomar muy buenas fotografías a la fachada del Parque del Calvario, el ex callejón $\mathrm{K}$-, creo que este ejemplo puede significar un aporte a la preocupación de Glusberg. No sólo podemos leer los textos explícitos sobre la adopción de determinadas actitu- 
des de diseño de CRV, también podemos entender algo de nuestra capacidad para ubicamos en la tarea real. Recordando que CRV conoció personalmente el Karl-Marx-Hof de Viena, deducimos que su punto de vista está fortalecido por experiencias directas. Esto es importante, sin duda. Es importante, además, que el artista ha sabido insistir sobre una manera de hacer las cosas que no dependía de una corriente, por más respetables que fuesen sus representantes. En esa época, Sibyl Moholy Nagy estaba en Caracas, junto con Vasareli, Calder y otros grandes artistas modernos, trabajando en la instalación de las maravillosas obras de arte, junto con CRV, en la realización de su obra de la Ciudad Universitaria de Caracas. Ella, Sibyl Moholy Nagy, veía el Silencio y tenía su propio juicio. Conviene decir esto, pues nos acerca: quizá en otras circunstancias, la ilustre diseñadora no hubiera tenido interés en la obra de CRV, por ejemplo, si no hubiera ido a Caracas. En caso de haber visto alguna vez una ilustración de $E l$ Silencio, hubiera supuesto que era un interesante ejemplo de arquitectura exótica de un país periférico, very tropical land. Su actilud cambió durante su permanencia allá, pues pasó a ser actora, se comprometió. A entender y a expresar con su autoridad profesional su opinión sobre una obra que no es común, pues los hechos no eran corrientes. El Silencio es, por ello, algo más que un documento de una posible arquitectura nacional venezolana. Es sencillamente arquitectura. Si es así, así debemos estudiarla y entenderla. Nuestra teoría puede ganar con ello, demás de que podría romper fronteras nacionales.

Para redondear el pensamiento en todos los niveles, podría referime a una gran cantidad de proyectos que no se han realizado pero que han tenido la misma inquietud. Hablo de todo el período de este siglo. Y en la última etapa, nuestro posmodemo, tenemos una oportunidad para revisar nuestras posiciones. ¿Quién puede negar que CRV defendió el racionalismo en su proyecto de $E l$ Silencio? El hecho de haberle introducido algunos elementos herejes -que es el sabor de la palabra ecléctico en el purismo racionalista- no lo hacen culpable de la esterilidad del funcionalismo y del international style.

Mis escuetos comentarios: mi sensación al visitar el proyecto fue de vitalidad. Y no es necesario hacer comparaciones; a lo sumo, quizá, paralelos: los portales estaban activos, llenos de vida $-y$ seguramente ante los ojos de la burguesía pacata - infestados de informales. Las fachadas blancas eran un alegato contra la ceguera y estupidez del tránsito rápido de autos por la Avenida Sur 8. Las fachadas abalconadas hacia el Parque El Calvario rebosaban de flores y sol y me imagino que las vistas desde allí hacia los árboles que subían la ladera deben ser hermosas. El Parque lo es. Los grandes patios estaban siendo usados y se mantenían arbolados y amables. No vi ningún apartamento, no quise. Esa imagen urbana era un regalo; después seguí en la Caracas de las autopistas petroleras... Alguien hizo el comentario: " ¿será que los críticos no aceptan la obra por ser vivienda obrera...? ... Si estuviera en Chacaíto..." (Así se llama la city caraqueña, sólidamente pacata y anónima). 


\section{Teoría y práctica de urbanismo en América Latina}

Mi primer impulso había sido poner una cruz en el cuadrito NO HAY. Por el momento no lo he retirado todavía. No existe una teoría sobre la actual ciudad latinoamericana, en el sentido que la entendemos: casi siempre ligada a la práctica y, a veces, como mero comentario de ésta. Nos quejamos de no tener ciudades de elevada sofisticación y operacionalidad. Aparte de las dificultades como método, interdisciplinariedad, instrumentos, etc. está nuestra especial forma de organizar el conocimiento: una mezcla de racionalidad y sensibilidad, ya lo mencionamos. Es algo, en principio, saludable y se puede decir que no puede haber aprehensión del universo sin la unión de esos dos aspectos de nuestra intelectualidad. Corresponde, sin embargo, anotar que los procesos que mantienen activos esos dos aspectos están demasiado a menudo interrumpidos $y$, en ocasiones, bastante abandonados.

El abandono o la interrupción son quizá los inconvenientes más graves para la consolidación de una teoría, que se supone debe llegar a saludables niveles de abstracción. La más elemental de sus definiciones es: teoría, conocimiento especulativo considerado con independencia de toda aplicación; o serie de leyes que sirven para relacionar determinado orden de fenómenos; o hipótesis, cuyas consecuencias se aplican a una ciencia o a parte muy importante de la misma.

Estoy convencido de algo: hoy podemos decir que sabemos de arquitectura y urbanismo latinoamericano mucho más que hace veinte años. Creo, sin embargo, que no hemos podido formular un postulado urbanístico que no se apegue a las concepciones generalizadas del mundo moderno capitalista. Indudablemente no hay evasión y $\rightarrow$ mal o bien definidos - la globalización y el neoliberalismo nos dirigen y dominan. Y como así será de aquí en adelante, me atrevo a proponer el abandono de cierlas utopías, mejor dicho, a dejarlas como están. Algunos autores no creen que ni siquiera seamos capaces de formularlas con precisión, o de siquiera preocupamos por ellas. Esa apatía (el arquitecto peruano Willi Ludeña, residente en Hamburgo, escribió un tomito: De la u-topía a la a-patia) de parte de los profesionales especializados se justifica, pues no existen directivas generales que los condicionen en su trabajo. $¿ O$ acaso es una directiva el siguiente texto (quizá algo aburrido, pero necesario conocer para probar nuestra capacidad de leoría)?

El PLAMADUR (Plan Maestro de Desarrollo Urbano) tiene su base de sustentación en los principios filosóficos del actual modelo de desarrollo económico sustantivados en la política urbana, la que deja muy claro que el Gobiemo será facilitador de este proceso, por supuesto siempre y cuando se tengan presentes las leyes de funcionamiento del libre mercado. La política urbana se plantea como propósito fundamental... "la búsqueda de una mayor competitividad económica en un ambiente de integración al mercado mundial"; por lo tanto, hay un principio rector en esta política urbana que se denomina "la ciudad competiti- 
des de diseño de CRV, también podemos entender algo de nuestra capacidad para ubicamos en la tarea real. Recordando que CRV conoció personalmente el Karl-Marx-Hof de Viena, deducimos que su punto de vista está fortalecido por experiencias directas. Esto es importante, sin duda. Es importante, además, que el artista ha sabido insistir sobre una manera de hacer las cosas que no dependía de una corriente, por más respetables que fuesen sus representantes. En esa época, Sibyl Moholy Nagy estaba en Caracas, junto con Vasareli, Calder y otros grandes artistas modemos, trabajando en la instalación de las maravillosas obras de arte, junto con CRV, en la realización de su obra de la Ciudad Universitaria de Caracas. Ella, Sibyl Moholy Nagy, veía el Silencio y tenía su propio juicio. Conviene decir esto, pues nos acerca: quizá en otras circunstancias, la ilustre diseñadora no hubiera tenido interés en la obra de CRV, por ejemplo, si no hubiera ido a Caracas. En caso de haber visto alguna vez una ilustración de $E l$ Silencio, hubiera supuesto que era un interesante ejemplo de arquitectura exótica de un país periférico, very tropical land. Su actitud cambió durante su permanencia allá, pues pasó a ser actora, se comprometió. A entender y a expresar con su autoridad profesional su opinión sobre una obra que no es común, pues los hechos no eran corrientes. El Silencio es, por ello, algo más que un documento de una posible arquitectura nacional venezolana. Es sencillamente arquitectura. Si es así, así debemos estudiarla y entenderla. Nuestra teoría puede ganar con ello, demás de que podría romper fronteras nacionales.

Para redondear el pensamiento en lodos los niveles, podría referirme a una gran cantidad de proyectos que no se han realizado pero que han tenido la misma inquietud. Hablo de todo el período de este siglo. Y en la última etapa, nuestro posmoderno, tenemos una oportunidad para revisar nuestras posiciones. ¿Quién puede negar que CRV defendió el racionalismo en su proyecto de $E l$ Silencio? El hecho de haberle introducido algunos elementos herejes-que es el sabor de la palabra ecléctico en el purismo racionalista- no lo hacen culpable de la esterilidad del funcionalismo y del international style.

Mis escuetos comentarios: mi sensación al visitar el proyecto fue de vitalidad. Y no es necesario hacer comparaciones; a lo sumo, quizá, paralelos: los portales estaban activos, llenos de vida $-y$ seguramente ante los ojos de la burguesía pacata - infestados de informales. Las fachadas blancas eran un alegato contra la ceguera y estupidez del tránsito rápido de autos por la Avenida Sur 8. Las fachadas abalconadas hacia el Parque El Calvario rebosaban de flores y sol y me imagino que las vistas desde allí hacia los árboles que subían la ladera deben ser hermosas. El Parque lo es. Los grandes patios estaban siendo usados y se mantenían arbolados y amables. No vi ningún apartamento, no quise. Esa imagen urbana era un regalo; después seguí en la Caracas de las autopistas petroleras... Alguien hizo el comentario: "¿será que los críticos no aceptan la obra por ser vivienda obrera...? ... Si estuviera en Chacaíto..." (Así se llama la city caraqueña, sólidamente pacata y anónima). 


\section{Teoría y práctica de urbenismo en América Latina}

Mi primer impulso había sido poner una cruz en el cuadrito NO HAY. Por el momento no lo he retirado todavía. No existe una teoría sobre la actual ciudad latinoamericana, en el sentido que la entendemos: casi siempre ligada a la práctica y, a veces, como mero comentario de ésta. Nos quejamos de no tener ciudades de elevada sofisticación y operacionalidad. Aparte de las dificultades como método, interdisciplinariedad, instrumentos, etc. está nuestra especial forma de organizar el conocimiento: una mezcla de racionalidad y sensibilidad, ya lo mencionamos. Es algo, en principio, saludable y se puede decir que no puede haber aprehensión del universo sin la unión de esos dos aspectos de nuestra intelectualidad. Corresponde, sin embargo, anotar que los procesos que mantienen activos esos dos aspectos están demasiado a menudo interrumpidos $y$, en ocasiones, bastante abandonados.

El abandono o la interrupción son quizá los inconvenientes más graves para la consolidación de una teoría, que se supone debe llegar a saludables niveles de abstracción. La más elemental de sus definiciones es: teoría, conocimiento especulativo considerado con independencia de toda aplicación; o serie de leyes que sirven para relacionar determinado orden de fenómenos; o hipótesis, cuyas consecuencias se aplican a una ciencia o a parte muy importante de la misma.

Estoy convencido de algo: hoy podemos decir que sabemos de arquiteclura y urbanismo latinoamericano mucho más que hace veinte años. Creo, sin embargo, que no hemos podido formular un postulado urbanístico que no se apegue a las concepciones generalizadas del mundo moderno capitalista. Indudablemente no hay evasión y -mal o bien definidos - la globalización y el neoliberalismo nos dirigen y dominan. Y como así será de aquí en adelante, me atrevo a proponer el abandono de cierlas utopías, mejor dicho, a dejarlas como están. Algunos autores no creen que ni siquiera seamos capaces de formularlas con precisión, o de siquiera preocuparnos por ellas. Esa apatía (el arquitecto peruano Willi Ludeña, residente en Hamburgo, escribió un tomito: De la u-fopía a la a-patía) de parte de los profesionales especializados se justifica, pues no existen direclivas generales que los condicionen en su trabajo. $i \mathrm{O}$ acaso es una directiva el siguiente texto (quizá algo aburrido, pero necesario conocer para probar nuestra capacidad de leoría)?

EI PLAMADUR (Plan Maestro de Desarrollo Urbano) tiene su base de sustentación en los principios filosóficos del actual modelo de desarrollo económico sustantivados en la política urbana, la que deja muy claro que el Gobiemo será facilitador de este proceso, por supuesto siempre y cuando se tengan presentes las leyes de funcionamiento del libre mercado. La política urbana se plantea como propósito fundamental... "la búsqueda de una mayor competitividad económica en un ambiente de integración al mercado mundial"; por lo tanto, hay un principio rector en esta política urbana que se denomina "la ciudad competiti- 
va", que tratará de aumentar la "capacidad de la ciudad para hacerle frente al desafío de una economía global".

La política urbana, presentada por el VMVDU a través de la Oficina de Planificación Estralégica (OPES), refuerza mucho más la idea de la ciudad competitiva cuando plantea que en relación con ésta hay que tener en cuenta cinco criterios básicos: "(a) las ventajas competitivas son, en gran medida, creadas; (b) la competitividad no sólo es producto de las acciones que lleva cada empresa a nivel individual, también es resultado del entomo de la ciudad; (c) la competencia debe estar completada con políticas sectoriales; (d) hay que conjugar acciones públicas y privadas; $(e)$ forlalecer la capacidad productiva" (Carta Urbana 44, mayo, 1996, pp. 5-6).

Siguiendo con la compulsa del documento citado, el porqué del PLAMADUR se condensaría en los puntos enunciados a continuación: economía urbana; aspectos ambientales; desarrollo urbanístico; la pobreza; la descentralización. (7). $\mathrm{Y}$ sus componentes estarían expresados en los Tipos de Planes siguientes. (a) Generales: Plan de Ordenamiento Ambiental; Plan de Ordenamiento Territorial. (b) De Area: Plan de rescate del centro de la ciudad. Plan de Mejoramiento de Barrios y las áreas abiertas. (c) De Sector: Plan de Manejo de desechos sólidos y saneamiento de aguas residuales. (d) De Inversión: Programa de fortalecimiento de Instituciones. Programa de inversiones estratégicas. (9) Algunos comentarios de la misma fuente. Respecto a ello, existen dos planes directores: el Plan de Ordenamiento Ambiental y el Plan de Ordenamiento Territorial, que responden básicamente al análisis socioeconómico del AMSSA, que determinó que los problemas más graves que afectan esta configuración espacial metropolitana y que pueden causar daños y cambios de carácter estructural son consecuencia de un desarrollo desequilibrado, concentrador, excluyente y depredador del medio ambiente. Y más adelante expresa que estos planes generales se complementan con los siguientes planes específicos: el Plan de recuperación del centro de la ciudad, el Plan de mejoramiento de barrios, el Plan integral de áreas abiertas, ... (10)

Por razones que no presenta el PLAMADUR, éste propone una "Super AMSSA" organizada en tres partes íntimamente articuladas: el área central, constituida esencialmente por el Municipio de San Salvador y los municipios que estrucluran un tejido urbano continuo; los municipios del primer cinlurón, estrechamente relacionados con el área central pero que conservan sus propias características; los municipios metropolitanos, más lejanos y casi lísicamente separados del área central, con polencialidades de organización autónoma.

De las consideraciones preliminares que hace el documento extraemos las que tienen relación con nuestro tema: $(b)$ el aumento de los perimetros urbanizados viene, por lo general, acompañado de un alza en los precios de la tierra. ¿Cómo se controlará ese fenómeno? (c) Si no se logra una adecuación de la totalidad de la estructura espacial urbana, de carácler integral en el corlo plazo, 
los problemas se van a dimensionar de tal forma que el control de los mismos por parte de los administradores territoriales será desbordado, y si a esto le articulamos la violencia urbana, la pobreza, etc., ¿qué pasará con la gobemabilidad de la ciudad? (e) Está clara la importancia que se le da a la relación con el medio ambiente, como parte esencial del PLAMADUR, con la idea de garantizar la sostenibilidad de la ciudad desde una perspectiva ecológica. Pero es necesario, por lo tanto, pensar invertir primero en aquellos soportes materiales urbanos básicos para los sectores más pobres: viviendas, alcantarillados, acueductos, salud, educación, etc.; se tendría que invertir en el mejoramiento de los asentamientos marginales y su integración al tejido urbano, con creatividad y participación, conservando y desarrollando las identidades barriales si se quiere pensar en un desarrollo urbano realmente sostenible.

¿Cuál es el estado de cosas ahora que terminó el trabajo de PLAMADUR y todo está en manos de la Alcaldía a través de sus oficinas? No puedo más que hacer unas preguntas con el título de "ies cierto que..." - ¿el Plan trabajó sobre bases cuestionables suministradas por el organismo público? ¿EI Plan ha dejado indicaciones normativas de cómo manejar el terrilorio afectado por su acción? - ¿Las hipótesis y tesis de trabajo no han sido adecuadas a los datos recibidos o a las expectativas? ¿El personal de los organismos oficiales no es eficiente para manejar las recomendaciones del Plan? Sin duda que un paquete de preguntas de esa importancia deben preocupar al público y a los profesionales. Pero, ¿es que un Plan puede acertar en esos puntos?, ¿y un personal burocrático/tecnocrático municipal puede actuar eficientemente en tareas para las cuáles no ha sido jamás calíficado? ¿No es más apropiado preguntar qué quiere significar el gobierno de El Salvador con tesis filosóficas como las de la 'ciudad competitiva'?

La fuente de todos los fracasos estará en el desentendimiento del sector oficial sobre los problemas crónicos de la ciudad de San Salvador. El mayor acto de voluntarismo político está en ello y en el carácter decretivo que se siente en los puntos $(a),(b),(c),(d)$ y $(e)$ considerados criterios básicos.

"¡Bueno, hagan un plan!" se titula un artículo escrito con motivo de la planificación del nuevo Berlín después de la Reunificación, posterior al derrumbe de la República Democrática Alemana. Parafraseando ese título digo: "entonces, ¡hagan el PLAMADUR!". Se sabe que los universitarios somos un tábano en el lomo de los inversionistas. Por cierto, ellos creen que están justificadamente haciendo uso de sus derechos de ciudadanos libres. Me gustaría partir de tomarle el guante a ese desentendimiento y considerar como muy irresponsable la actitud de un gobiemo que deja todo en manos de los inversionistas.

Esto me permite justificar mis ataques desde el punto de vista del vencido. Como esa justificación es bastante conocida en nuestros medios profesionales urbanos -que dejan de lado los problemas de los campesinos, como si ellos formaran parte de otro país-, pienso que me interesaría revisar un poco nuestra 
(in-) capacidad como urbanistas. Por lo que recuerdo, la teoría urbana que nos enseñaron - $\mathrm{y}$ que veo que subsiste, la de las funciones urbanas - sigue marcando la problemática planteada al PLAMADUR. Este ha recibido de conformidad, pues es su manera de hacer las cosas. Sin embargo, la pregunta crucial: "¿qué tipo de ciudad tenemos?", no ha sido formulada. Se ha declarado el tipo de ciudad que queremos tener (ique vamos a tener gracias a la inversión privada y al mercado libre!) y existe un abismo entre ambas.

De los distintos comentarios sobre el caso de San Salvador y su PLAMADUR, hay uno que me parece sabio: encarar el problema por partes y con pequeñas realizaciones. Estas deben estudiarse en su realidad y no con proposiciones o metodologías inapropiadas. ¿Qué podemos exigir? Antecedentes precisos para el análisis y el expediente urbano, lo cual implica no sólo la escala macro, sino además la de intervención, o sea, la localización micro. Por ejemplo, si tenemos que tratar el tema barrancas, se elige una, se despeja de sus problemas actuales, se analiza en todas sus partes y se incluyen los problemas cuando sepamos qué hay en ellas y no solamente antes. ¿Qué significa? Relevamiento de su aspecto geográfico, catastro de su modificación, o sea, construcciones, movimientos de tierra, obras de infraestructura, vegetación, edificaciones que pormenorizan su característica, uso, número de ocupantes y lodas las demás anotaciones de un verdadero censo. Con esos antecedentes se investigan los mélodos más apropiados de intervención, y se fijan tareas, plazos, medios y resultados. Esas obras de análisis, diseño y previsión de realizaciones deben estar garantizadas por un determinado tipo de contrato, anclado en alguna ley y sujetos a sanciones en caso de desconocimiento de ellas.

\section{Crílica al modelo}

Ese modelo que tomamos (PLAMADUR) es el del poder centralizado. Operar la descentralización a partir de un centro, ¿no es un absurdo? Y, sin embargo, con ese postulado absurdo pretendemos crear las condiciones de la ciudad comperitiva, o cualquier otro modelo de ciudad altemativa. Sin duda, el discurso para poder entendernos y no desentendemos debería ser el del modelo de ciudad.

¿Cuál es nuestro modelo histórico? Nuestra historia urbana desde el descubrimiento de nuestras costas, y al inicio de la colonización, después de la conquista, es el relato de la sucesión de fundaciones fortificadas mal o bien para el ejercicio del poder. El poblamiento era secundario. Quienes debían habitar eran soldados y soldaderas, la fundación era un campamento militar, su funcionamiento el de un cuartel. La supremacía de la raza blanca no debía estar nunca en juego. El poder blanco debía primar. La ciudad debía ser de un modelo europeo. Esa es una parte del origen de nuestra identidad. A ello no pertenecían los pueblos de indios. 
El discurso republicano a partir de 1820 , mestizo en su mero origen, es acomplejado, pues la parte blanca niega la parte no blanca, sea esta india o negra, amarilla o de origen levantino (fundamentalmente sirio-libanés). Esa es la otra parte de nuestra identidad. La historia de la ciudad republicana es un seguimiento atrasado en medio siglo o más del modelo europeo. Pero nunca la ciudad copia fue como el modelo, ni pudo ni puede. Hemos llenado la ciudad copia de objetos de la ciudad modelo pero no hemos logrado que tenga capacidad para autorregularse, mal o bien. La ciudad modelo funciona a un elevadísimo costo humano y monetario. En el centro de bastantes ciudades norteamericanas, en donde la única pauta para el mantenimiento de un centro urbano es el rendimiento de la inversión, si ésta no se justifica es más conveniente dejar caer en ruinas la parte que no rinde e invertir en terreno más económico. ¿No sucede esto acaso hoy en San Salvador? No nos ayuda el discurso salvacionista: el que invierte quiere tener beneficios. ¿Puede el Estado garantizarlos? ¿Estas son preguntas para urbanistas? Es que ahora el modelo de la época industrialista no sirve más. La ciudad se va convirtiendo en un lugar no rentable. Antes, al albergar al actor productor por excelencia, el proletariado, debía funcionar. La pequeña burguesía exigía modestamente su rincón para abastecer al proletariado y el gran industrial aceptaba. La ciudad burguesa y pequeño burguesa debía ser aceptable, gregaria y conscientemente clasista. La burocracia estalal estaba anclada en el poder.

Si consideramos las tendencias de producción de la globalización, nos damos cuenta de que el discurso de la ciudad competitiva se reduce a permitir instalar maquilas en zonas francas. ¿Qué más pretende el inversionista? La ciudad habitable por todos no puede ser financiada con las ganancias deslinadas a olras inversiones. Todo el capital, pasando por el filtro de la banca, tiene un destino que no es la inversión urbana. Qué es, no nos interesa; no es nuestro tema. Lo cierto es que no hay dinero para los planes. Entonces, si queremos construir en la ciudad buscamos la ayuda exiranjera, la que se nos da con desconfianza. Es necesario controlamos, no vaya a ser que nos equivoquemos y gastemos su dinero en falsos proyectos. Nos convencen una vez más de que el modelo debe ser el que ellos enlienden, desarrollan, prueban, corrigen, reordenan y estatuyen. Nosotros ejecutamos las obras de ellos como obreros o - a lo sumo- como dibujantes y capataces. Esa es la última parte de nuestra identidad. Los proyectos para los cuales se recibe ayuda extranjera (o préstamos convenientes) no son suficientes para realizar el proyecto global de ciudad capital. Creo que a los universitarios nos corresponde estar conscientes de eso y asumir nuestra responsabilidad de formar arquitectos que, a su vez, lo estén a futuro.

¿Qué podemos hacer como investigadores del campo físico del urbanismo para solucionarlo?, plantearlo. El método más adecuado es la participación. Entonces deberíamos relacionamos con mayor frecuencia con los participantes, Lo cual, de hecho, es difícil. Así que propongo el desarrollo de un programa acadé- 
mico para investigar causas antes de aplicar soluciones a problemas derivados de aquellas causas. Por ejemplo, el tránsito y el transporte están relacionados con la localización de los puestos de trabajo y de las viviendas; el cortoplacismo de las soluciones técnicas nos descalabra cada vez más el tejido urbano, o sea, la esencia de nuestro proyecto. $Y$ no es sólo el tejido urbano el que se compromete, es el conjunto de eso que tan acertadamente Frederick Gibberd llamó paisaje urbano (townscape) y que no debe confundirse con veleidades decorativas. Si hablamos de barrancas o quebradas, que fueron el recurso natural para la regulación de las aguas lluvia en el paisaje tectónico centroamericano, es urgente trabajar en ellas más que en autopistas; saber que un parque es bueno pero que las laderas y colinas son fundamentales. Que los fondos de manzana pueden taponarse con condominios de último momento, destruyendo los pulmones urbanos y los basurales destruir los biotopos de una ciudad sana hasta hace menos de veinte años sin que podamos impedirlo. Que no debemos permitir que valga más un car-wash que un jardín. Una reja que un seto de ligustros, etc., etc. Supongo que éstos son problemas que no se presentaban antes y que no se dan igual para un sector muy grande de la población: el de la miseria.

La gente necesilada, la gente en la miseria, necesila lo esencial. Y si a pesar de saberlo no podemos suministrarlo, nuestro saber es inoperante. Si ustedes invitan a un villero a participar, él/ella espera ayuda inmediata. No le interesa la investigación. Lo fundamental lo sabe: le va mal. ¿Cuales son las posibilidades de realizar un proyecto piloto que no esté plagado por la política, por el favoritismo, dependiendo del control de la ayuda extranjera? Sólo puede venir de una instancia responsable. Debemos y podemos pensar en lo que nos rodea. No tenemos soluciones para mejorarlo. Podemos construir al lado lo que queremos tener y decir que eso es la ciudad competitiva. Trazamos líneas sobre planos más o menos detalladas de nuestras calles, rodeando manzanas y parques; zonificamos, remodelamos, rehabilitamos. En el plano del diseño urbano tenemos la imagen de un modelo que funciona allá lejos, donde ubicamos el paraíso tertenal del urbanismo. El calor, el olor, el gusto de nuestra realidad quedan en la puerta de nuestro estudio de urbanistas. Del lado de afuera. Nos miran, no nos escuchan, pues la puerta está cerrada. La entreabrimos y hablamos de participación.

\section{Brasilia}

Prometí volver a hablar de Brasilia. Es muy difícil que haya existido una teoría urbana específica para Brasilia. Hubo un postulado de poder gubernamental, y aunque el desarrollo urbano en Brasil haya sido muy distinto del de la región hispanoparlante, la idea del poder central no estuvo ni está ausente de sus realizaciones. Más aún, contrariamente a las otras naciones del continente sudamericano, Brasil es la única que tiene en su constitución originaria el traslado de la capital a la región prefijada donde se construyó la nueva capital. Pero, 
semejante a todas las otras naciones del continente, tiene una profunda vocación centralista.

Ya llevamos casi medio siglo discutiendo sobre su acierto o desacierto. Posiblemente sea una discusión desacertada. El conjunto de desaciertos de Brasilia no está en su forma, sino en ser la forma física de la expresión del poder omnímodo de una democracia que no es tal. Por ello, criticar sus partes arquitectónicas de una exquisitez formal innegable es tiempo perdido. Es la única ciudad del ambiente latino que tiene una voluntad por sí misma, que no necesita justificarse por su función, aunque sea la máxima de ser la capital del Estado. La nación brasileña se ve en ella, aunque es lo menos brasileño que puede haber.

Discutir su razón de ser desde ese punto de vista es un juego bizantino. Sin embargo, veamos qué es esa ciudad. Porque de algo podemos estar seguros: no se repetirá y, en ese sentido, nos obliga por mera conciencia de conocer. Los trabajos de crítica que se han hecho están dirigidos a dos errores graves: la abstracción de su diseño y su desacierto climático. Según el proyecto político, no son errores. El primero no lo sería, pues precisamente se necesitaba un diseño que no apelase más que a la idea abstracta suprema: sede del poder central de la nación brasileña. Nada de regionalismos estilísticos, no importa de qué tipo. Ni Bahía ni Río ni San Pablo. Ni camaval ni droga, ni gaúchos ni cangaçeiros. El segundo está negado, pues no es una ciudad para personas sino para funcionarios. Mucho tiempo se ha tratado de atacar más por ese aspecto y, en verdad, se han señalado dos o tres fenómenos urbanos negativos: el deterioro de ciertas zonas del hábitat de los funcionarios y el crecimiento de la pobreza marginal. Frente a esa situación, de hecho el responsable, el gobierno de Brasil, no ha considerado necesario hacer ningún comentario. Quedará como uno de los casos de las grandes aglomeraciones. ¿Se hubieran podido prever esos problemas? Y si así hubiese sido, ¿se hubiera podido encontrar una solución que los impidiera? La primera pregunta es lógica; seguro que se podían prever y de hecho Lucio Costa, su creador arquitectónico urbanístico, tenía suficiente vida y experiencia como para no negarlos. Lo mismo Oscar Niemeyer, de militancia comunista. ¿Encontrar una solución? No, obrigado.

Otros intentos han habido y fallado. A una escala semejante pero indudablemente menor, Argentina trató en repetidas oportunidades de trasladar su capital. En un primer caso hacia el centro geográfico del país, en otra hacia un punto central de la larguísima costa atlánlica. Ambos proyectos fueron desechados por falta de consenso en las Cámaras, o sea, por falta de poder central. ¿Habla eso de una mejor interpretación de la democracia?, no lo sé. Muchas veces hemos pensado que la ciudad nueva nos ayudaría a una vida nueva. Parece no ser así. Por tanto, seguiremos con las que tenemos hasta que se dernumben o las destruyamos, nosolros o los agentes climáticos. Pero antes de eso digamos algo sobre antropología urbana. 


\section{6. ¿Cuál es nuestro comportamiento en la ciudad?}

Muchas veces hemos pensado que la ciudad nueva nos ayudaría a una vida nueva. Aldo van Eyck tuvo la presencia de ánimo de describir y pensar la dimensión no europea del hábilat humano y por ahí repensamos. Pero pronto, exagerando el entusiasmo, todos ansiábamos ir a alguna aldea africana, alejada de la civilización, aunque haciendo votos para que ésta no nos olvidara. Las fallas de relación espacial en los proyectos surgieron como por encanto cuando los comparábamos con esas maravillas de tradición y espontaneidad, de color y forma, de rango social, de significado arquileclural y urbano para toda la sociedad en las aldeas africanas. Convencidos de que eso se había dado por la eliminación de factores no racionales en los procesos de diseño, nos sentimos abandonados por todas las musas y decidimos abandonar la arquitectura. Nuevas corrientes se impusieron $y$, partiendo de discursos nihilistas, se fue haciendo camino una corriente neohistoricista - el posmodemo- que permitió a los nuevos constructores ofrecer a los inversionistas un producto desemantizado, fresco y apto para una competencia en donde la meláfora era obvia: el triunfo del capital. Los temas se complicaron, ya no en un proceso de adaptación a un mundo que progresaba técnicamente, sino en un escenario prescindible, en donde lo físico-real se mimetizaba con la realidad virtual que ya podían resolver con brillantez los operadores de computadoras. Es posible que eso hiciera prescindible al arquilecto.

Pero no son sólo los arquitectos los que estarán en condiciones de reorientar la arquitectura para acompañar los cambios que está sufriendo la sociedad de los países desanrollados. Por primera vez en la historia, los sociólogos y antropólogos europeos hacen un serio llamado a los países ricos sobre el alarmante deterioro del planeta (Levi Strauss, Amos Rapoport, Pierre George). En esos años tuvo sus inicios el estructuralismo y la semiología, una ciencia de explicación de la contextualidad en filología. Gillo Dorfles escribió sobre este tema: Estructuralismo y Semiología en Arquitectura. Fue una época de la crisis de creatividad de mayor trascendencia en la historia arquitectónica del siglo XX. En el desconcierto general y la desazón social por la pobreza intelectual, otros investigadores buscaron nuevos caminos que pudieran ayudar.

Amos Rapoport me ha enseñado, en los libros que he citado a lo largo de este artículo, que es necesario establecer fórmulas simples, conocidas y cotidianas para, a partir de esa base, iniciar una especulación sobre lo obvio y lo recóndito. Y respecto a las ciudades del gran hermano del Norte dice:

"Las diferencias entre el entorno construido de Estados Unidos, Francia e Inglaterra pueden comprenderse a la luz de la actitud americana del laisez-faire (dejar hacer, en francés en el original AR.) abierto y orientado sobre el desarrollo a la luz de la tradición urbana francesa que no afecta solamente la ciudad, sino que modifica también el paisaje rural por sus cualidades 'urbanas', y a la 
luz de la tradición inglesa 'anti-urbana' que permite explicar el carácter de numerosas regiones urbanas de este país. Es por eso que se sigue buscando el entomo ideal del cual la casa es simplemente una encarnación; $y$ es por eso que en Estados Unidos se da recientemente (1969) la tendencia de construir inmuebles y 'ciudades nuevas' alrededor de zonas de esparcimiento, lo que es una franca transposición de un viejo ideal bajo una apariencia nueva" (Amos Rapoport, Pour une Anthropologie de la Maison, 1969, p. 176).

¿Cómo es posible eso en el país que ha instiluido el rascacielos como su modelo urbano? Error. El rascacielos no es un modelo urbano, ni siquiera arquitectónico. Es un símbolo de poder económico. Desplazando al majestuoso Congreso Jeffersoniano con su omnipresente cúpula, el rascacielos es la manifestación de una nueva lucha por un nuevo poder: money. Lo que fue San Gimigniano con las torres de los señores de tradición heráldica, sería Manhattan con sus lanzas de dólares. Pero, jojo! E.l remedo es fatal. Ningun urbanista latinoamericano tiene porqué suponer que está formando identidad urbana con esos monstruos. Y para que nos entendamos: los ciudadanos de esas ciudades con monstruos son como son por tener esos monstruos. Quiero decir, la arquitectura de un rascacielos es primitiva. Por contraposición, su valor simbólico es enorme. El comporlamiento de un urbano, respaldado por un rascacielos, es insuperable.

Un componente que no debemos dejar de mencionar es el de las 'culturas hibridas', un término que nos ayuda a llenar un vacío muy grande dejado por los investigadores de la sociología urbana laboral de la época de Manuel Castell, el del comportamiento de los actores. Su presentador, Néstor García Canclini, ha estudiado el tema en su libro, cuyo sublítulo es igualmente sugerente: Estrategias para entrar y salir de la modernidad. Cualquiera de sus preguntas es un remezón para nuestro comodismo provinciano: " $¿$ Con qué recursos teóricos podemos repensar los usos sociales contradictorios del patrimonio cultural, disimulado bajo el idealismo que lo mira como expresión del genio creador colectivo, el humanismo que le atribuye la misión de reconciliar las divisiones 'en un plano superior', los ritos que lo protegen en recintos sagrados?".

Lo significativo de esta pregunta es, no sólo su profundidad, sino, además y precisamente la desacralización oficialista de tanto elefante blanco en nuestras culturas. La pregunta más general que se puede hacer sería: ¿qué se puede recibir a cambio con la hibridación? Si por una parte dejamos de ser latinos, cubanos, venezolanos, salvadoreños, por otra somos ¿qué? Una consideración realista es que somos eso justamente, se llame como se llame. Porque si nosolros, los que vivimos en tierras latinoamericanas nos quejamos de pérdida de identidad, en los países donde viven cada día más latinos, ellos exigen que se los deje serlo, usar su idioma, tener sus prácticas. Con ese material real y sin el lastre salmódico de los postulados morales y patrióticos estaríamos analizando la hibridación. 
Creo que es por eso, porque somos culturas híbridas. El funcionalismo, como lo concebíamos en los años anteriores a la gran diáspora, ya ha dejado de tener valor debido a que en lugar de ser una teoría de diseño arquitectónico, pasó a ser un manual de soluciones estereotipadas. Si volvemos a la formulación expresada anteriormente: debemos hacer coincidir la necesidad con el resultado, más nos conviene diseñar según las necesidades que surgen de nuestra propia vida.

El ejemplo más usado es el de la casa. En diferentes cursos universitarios hemos podido observar la fijación que hay en los modelos de viviendas racional o funcional. Y no hay duda que las dificultades del proyecto no son derivadas por la interpretación del modo de usar la vivienda. Puede suceder, a menudo, que no se sepa muy bien cómo funciona una cocina. Entonces se apela a información gráfica y muchos han de preguntar a quienes saben. Dejemos de lado la cuestión de si a quienes preguntamos están en condiciones de responder. Aunque es posible suponer que si el diseñador se dedica con atención a ver cuáles son los procesos de cocinar terminará por aprenderlos.

A lo que yo me quiero referir con el tema de necesidad y resultado es a nuestra evidente incapacidad de diseñar para otro tipo de actores. La vivienda se diseña así porque la familia es así. En un ejercicio se supuso que el diseñador tenía libertad para imaginar el tipo de familia que usaría la vivienda diseñada. Los ejemplos con tipos de familias distintos no fueron interpretados como viviendas, sino como organizaciones para alojar a gentes pero no en condiciones de familia: no era imaginable suponer que cada miembro de la familia quisiera disponer de una habitación para él/ella solo/a, sin que pesara en el juicio el grado de parentesco.

Con esta dificultad para imaginarse usos sociales, resulta difícil hacer pensar a un grupo de diseñadores temas que no sean los que eslán acostumbrados a ver. Si el común de los usuarios, esa gran masa de gente que dice yo no sé nada de arquitectura pero... debiese expresar su opinión sobre un diseño cualquiera, no tendría obligación de hacer comentarios muy técnicos. Y precisamente esos son los comentarios que hace. La casa parece sólida o no, tiene buenos desagües $o$ malos, el alquiler es alto o no, etc. Es posible que nuestra cultura de apreciar una vivienda dependa de la libertad que tenemos de intervenir en su apropiación, en la modificación o serie de modificaciones que hacen que la sintamos nuestra. Las recomendaciones de las revistas del hogar tienden a ello. Aunque no estemos muy habituados a considerar que nuestra casa es un objeto moldeable según nuestras complejas necesidades físicas y anímicas, debemos hacer un esfuerzo para salir de algunos circuitos a veces perjudiciales para nuestra salud social. El ambiente tétrico de muchas casas se puede modificar con una actitud más creativa de sus ocupantes. Un ejemplo lo constituye el rincón de cada uno. Con el tiempo es posible decidir cuál es el lugar donde una persona de la casa se siente más 
cómoda. En ese caso se recomienda tener consultas de lodos los miembros de la familia para lograr algo que es lícito.

Esta flexibilidad en el uso de lo que nos es cercano, se trate de la casa o del lugar de trabajo, y en su posible transformación, nos puede ayudạr a entender que todos podemos opinar sobre los acontecimientos en sectores más amplios. La condición es que sepamos por qué lo hacemos. Y ese por qué casi siempre es un tipo de necesidad que quizá no hemos podido descubrir. En ello veo a una de las grandes oportunidades de la arquitectura. Es una práctica maravillosa que he conocido leyendo los libros de Rodolfo Livingsion, y no se crea que hablamos de un nuevo recetario. Es una actitud libre y creativa e igualmente intelectiva. Es posible sensibilizarnos en la vivencia de nuestro hogar en conjunción con nuestra responsabilidad de vivir cultamente en un mundo complejo. Si el problema de la belleza de la arquiteclura lo introducimos entre las decisiones por tomar para organizar la despensa de la casa, habremos avanzado como arquilectos y usuarios en nuestra incorporación a un mundo cada vez más rico en experiencias, no sólo prácticas, sino, y con mayor significación, intelectuales y estéticas.

América Latina ha dado un salto de un siglo en cincuenta años. Hoy no nos referimos sólo a ejemplos del norte. La arquitectura latinoamericana no se ha terminado con los maestros, se continúa en todas las latitudes y tenemos publicaciones que lo atestiguan. Los profesionales jóvenes están planteándose una nueva relación con el mundo del diseño. Los temas, aun cuando sean los mismos, se están resolviendo con más imaginación. Partiendo de la propia realidad resolvemos problemas que antes desechábamos por ser de poca trascendencia, por ejemplo, lo doméstico. Un conjunto urbano, como célula originaria de nuevas expansiones, tiene texturas arquitectónicas y urbanísticas aún en las condiciones más difíciles. Manejar diferentes escalas, presupuestos y condiciones sociales nos enseña que el espacio urbano es producto de una precisión en el planteamiento del problema y de la preocupación de joyero en su resolución.

San Salvador, septiembre 1998.

Nota

1. Este texto esı́á compuesto de diferentes secciones del libro de mi autoría Arquitectura del Siglo XX (inédito). Agradezco sinceramente al Lic. Héctor Samur por insistir en que el público me lea en su valiosa revista Realidad, en esta ciudad de San Salvador, a fines del mes de sepliembre de 1998. A pesar de que este artículo aporta una serie de decires en algunos momentos no bien correlacionados, es producto de conversaciones inolvidables con colegas, profesores y estudiantes en oportunidades diversas, a quienes deslindo de la responsabilidad de los errores y agradezco la valenlía de su imaginación. 


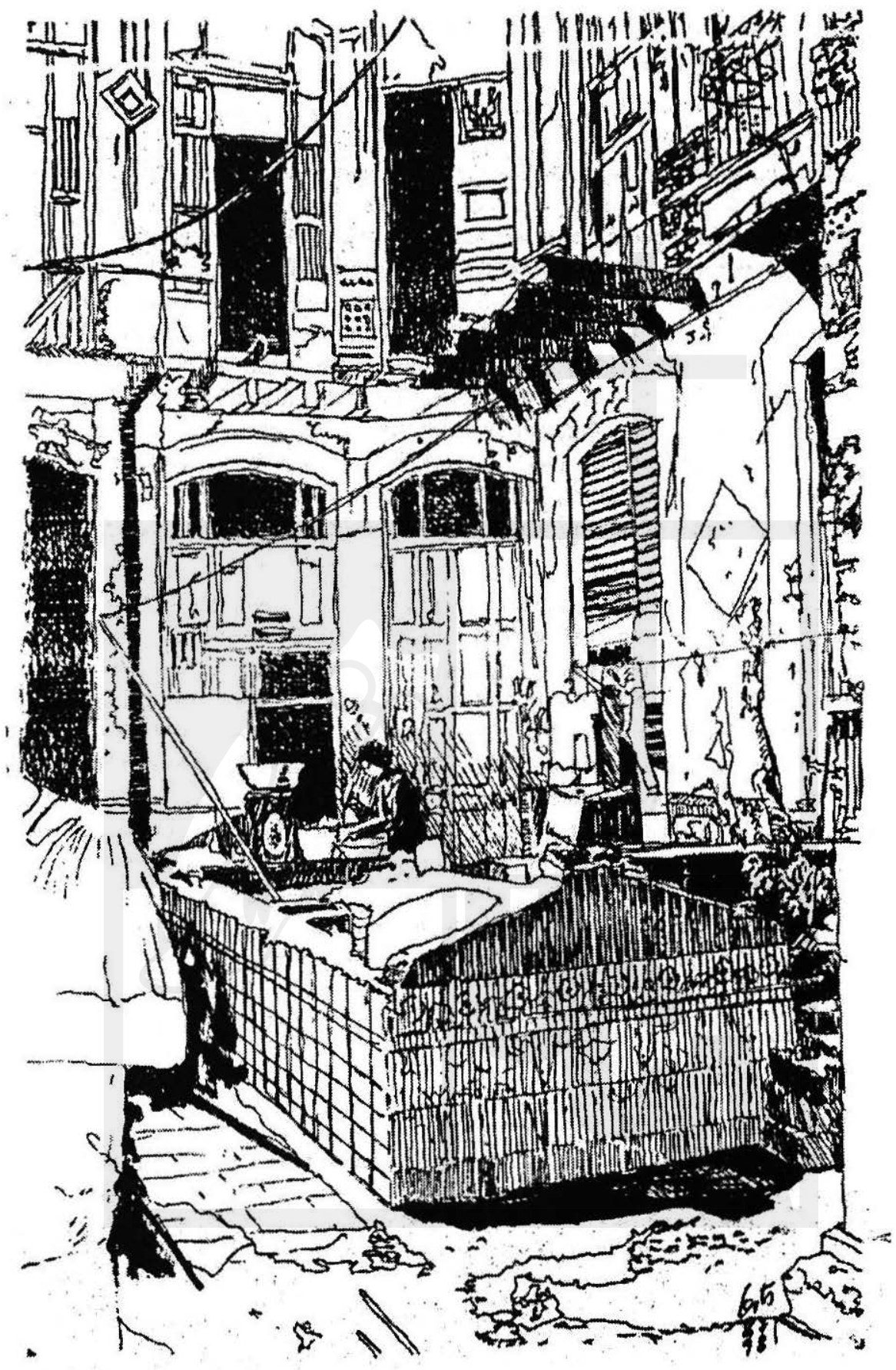

